\title{
Saúde, trabalho e imigração: revisão da literatura científica latino-americana
}

\author{
Health, work and immigration: Latin American scientific literature \\ review
}

Leonardo Dresch Eberhardt', Ary Carvalho de Miranda²

\begin{abstract}
RESUMO Este estudo tem como escopo a relação entre saúde, trabalho e imigração sob a perspectiva da determinação social. Trata-se de pesquisa bibliográfica realizada em setembro de 2015, com o objetivo de discutir a relação saúde-trabalho-imigração a partir da produção científica latino-americana. Foram incluídas 24 publicações. Os resultados indicam a precariedade das condições de vida, trabalho e saúde dos imigrantes. Foi observado que a produção latino-americana a respeito do problema tem incorporado de forma tímida a categoria trabalho, o que torna importante a realização de estudos que abordem a saúde dos imigrantes considerando o processo de determinação social.
\end{abstract}

PALAVRAS-CHAVE Saúde dotrabalhador. Saúde pública. Emigração eimigração. Trabalhadores.

ABSTRACT This paper discusses the relationship between health, work and immigration under the perspective of the social determination process. It is a literature review executed in September 2015, aiming to discuss the relationship between health, work and immigration starting from the Latin American scientific production. At the end of the selection process, 24 publications were included. The main results indicate a precariousness of the immigrants' life, work and health, which shows the importance of studies that address the health of immigrants considering the process of social determination.

KEYWORDS Occupational health. Public health. Emigration and immigration. Workers.

1Fundação Oswaldo Cruz (Fiocruz), Escola de Saúde Pública da Escola Nacional de Saúde Pública Sergio Arouca (Ensp) - Rio de Janeiro (RJ), Brasil. leonardodeberhardt@gmail. com

2 Fundação Oswaldo Cruz (Fiocruz), Escola de Saúde Pública da Escola Nacional de Saúde Pública Sergio Arouca (Ensp) - Rio de Janeiro (RJ), Brasil. ary@fiocruz.br 


\section{Introdução}

Cada vez mais, a questão da imigração ganha destaque no cotidiano social. Seja nos noticiários midiáticos, seja ao circular por algum centro urbano ou até em seu local de trabalho, a presença de pessoas provenientes de outros lugares do planeta se faz notória. Segundo dados da Organização das Nações Unidas (ONU), no ano de 2015, o número de imigrantes internacionais chegou a 244 milhões de pesSOas (UNITED NATIONS, 2016).

O Brasil, por exemplo, vive um boom imigratório desde o início do século XXI. Entre 2000 e 2010, o número de imigrantes internacionais no Brasil aumentou em 451,18\%, enquanto os Estados Unidos da América (EUA), país tradicionalmente receptor de fluxos migratórios, teve um crescimento de apenas $23,97 \%$ (UEBEL, 2016).

Em relação ao trabalho, os imigrantes têm sido atingidos massivamente pela precarização. No contexto do novo complexo de reestruturação produtiva do capital (ALVES, 2000), o exemplo dos imigrantes talvez seja o mais exacerbado da tendência estrutural à precarização do trabalho e é, para Antunes (2014), a 'ponta do iceberg' desse fenômeno: eles têm, em geral, os horários mais desconfortáveis, como jornadas noturnas e nos finais de semana, combinando salários mais depauperados, superexploração e discriminação. Ou seja, a inserção dos imigrantes no mundo do trabalho e nas sociedades receptoras pode trazer desafios significativos para a saúde pública.

Ao considerar o campo das relações entre trabalho e saúde e, no interior dele, na perspectiva da saúde do trabalhador (MINAYOGOMEZ, 2011), compreender o processo de saúde-doença relacionado com o trabalho dessas populações se torna crucial. Somente a partir disso, é possível a construção de estratégias de resistência e de proteção às condições de vida, trabalho e saúde dos imigrantes, tanto via políticas públicas quanto por movimentos sociais.

Neste artigo, parte-se da noção de 'determinação social da saúde' (FLEURY-TEIXEIRA, 2009; TAMBELLINI; SCHÜTZ, 2009) com o objetivo de discutir a relação entre saúde, trabalho e imigração a partir da produção científica latino-americana inserida no campo da saúde pública.

\section{Metodologia}

Este estudo adotou como método a revisão bibliográfica da literatura que, segundo Gil (2002), utiliza material já elaborado, como livros ou artigos, permitindo ao investigador a cobertura de uma gama ampla de fenômenos. A revista científica é, "nos tempos atuais, uma das mais importantes fontes bibliográficas" (GLL, 2002, P. 45).

A busca dos textos foi realizada na base de dados da Literatura Latino-Americana e do Caribe em Ciências da Saúde (Lilacs), no mês de setembro de 2015, utilizando-se as estratégias descritas no quadro 1 . Os seguintes critérios de inclusão foram adotados: artigos completos e originais disponíveis on-line gratuitamente, em português, inglês ou espanhol, sem qualquer recorte temporal. Foram excluídas as publicações que não possuíam resumo indexado na base de dados ou que não se adequassem à temática proposta.

Quadro 1. Estratégias de pesquisa utilizadas e número de resultados encontrados na base de dados

\begin{tabular}{lll}
\hline Base de dados & Estratégia & $\begin{array}{l}\text { Número de resultados } \\
\text { encontrados }\end{array}$ \\
\hline \multirow{2}{*}{ Lilacs } & "imigracao" [Palavras] AND "saude" [Palavras] AND "trabalho" [Palavras] & 447 \\
& "migracao laboral" [Palavras] AND "saude" [Palavras] & 102 \\
\hline
\end{tabular}

Fonte: Elaboração própria a partir da Lilacs, 2015 
Inicialmente, foram encontrados 549 resultados, dos quais 24 foram incluídos. Os procedimentos de seleção das publicações estão demonstrados na figura 1. As 24 publicações selecionadas foram lidas integralmente e fichadas em instrumento próprio, utilizando-se o Microsoft Word ${ }^{\circledR}$ 2007. Após a leitura e fichamento dos textos, os dados obtidos foram sistematizados em um quadro sinóptico, que continha as seguintes informações: referência, número de identificação, resumo, instituição de procedência dos autores, local de realização do estudo, país onde foi publicado, ano, objetivos, metodologia e principais resultados.

Figura 1. Fluxograma de seleção (inclusão e exclusão) dos artigos no estudo de revisão na Lilacs, 2015

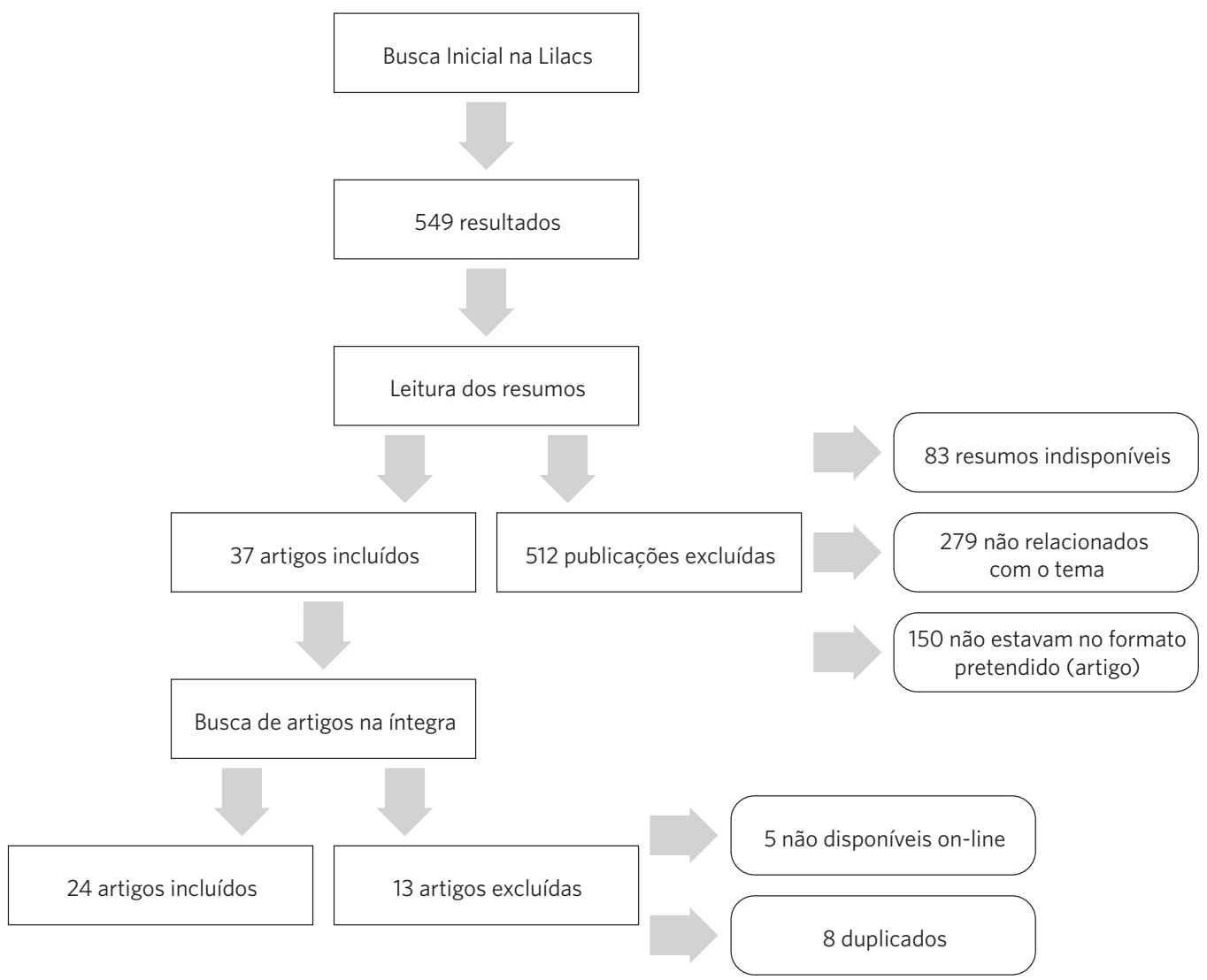

Fonte: Elaboração própria a partir da Lilacs, 2015

A análise dos achados foi realizada de modo qualitativo, seguindo-se as orientações de Minayo $(2008,2012)$. A partir do processo de compreender, interpretar e dialetizar os dados encontrados, foram construídas algumas categorias, que estão inter-relacionadas.
Os preceitos referentes aos direitos autorais e à ética em pesquisa foram respeitados. Em virtude da natureza bibliográfica do estudo, que utiliza apenas dados e informações de domínio público, não foi necessário apreciação por Comitê de Ética em Pesquisa. 


\section{Resultados e discussão}

Entre as 24 publicações selecionadas, todas estão no formato de artigo, publicadas em revistas científicas das áreas de saúde pública (12), enfermagem (4), ciências sociais (2), medicina (2), saúde materno-infantil (2), psicologia (1) e direito (1). Quanto à língua, 10 artigos foram publicados em inglês, 7 em português e 7 em espanhol. Contudo, a maior parte foi publicada no Brasil (13), seguido de Colômbia (3), EUA (3), Chile (2), México (1), Peru (1) e Jamaica (1).

Quanto à procedência do primeiro autor, a maior parcela está vinculada a instituições localizadas no Brasil (9), seguido de Chile (4), Espanha (3), México (2), EUA (2), Argentina (1), Peru (1), Alemanha (1) e Itália (1). Ou seja, apesar da maior parte dos estudos terem sido publicados em inglês, o Brasil é o país responsável pela maioria dos textos relacionados com a temática da relação saúde-trabalho-imigração indexados na Lilacs.

Em relação ao ano de publicação, todos os artigos pertencem ao intervalo entre 2004 e 2014. No entanto, apenas dois deles foram publicados antes de 2007: um em 2004 e um em 2005. Do restante (22), todos foram publicados a partir de 2007, o que pode indicar um crescimento no interesse pelo tema mais recentemente, possivelmente relacionado com o contexto global de mundialização econômica e cultural. O quadro 2 apresenta de forma sumária a distribuição das publicações incluídas no estudo, segundo autor, título, revista e ano.

\begin{tabular}{|c|c|c|c|c|}
\hline ID & Autores & Título & Revista & Ano \\
\hline 1 & Aguiar ME, Mota A. & O Programa Saúde da Família no bairro do Bom Retiro, SP, Brasil & $\begin{array}{l}\text { Interface: Comunicação, } \\
\text { Saúde e Educação }\end{array}$ & 2014 \\
\hline 2 & Ayala-Carrillo MR et al. & El trabajo infantil guatemalteco en los cafetales del Soconusco & $\begin{array}{l}\text { Rev. Latinoam. de Ciencias } \\
\text { Sociales }\end{array}$ & 2013 \\
\hline 3 & $\begin{array}{l}\text { Martes ACB, Faleiros } \\
\text { SM. }\end{array}$ & $\begin{array}{l}\text { Acesso dos imigrantes bolivianos aos serviços públicos de saúde na cidade } \\
\text { de São Paulo }\end{array}$ & Saúde e Sociedade & 2013 \\
\hline 4 & Hernando A, Nunes C. & $\begin{array}{l}\text { A comparative study on the health and well-being of adolescente immi- } \\
\text { grants in Spain and Portugal }\end{array}$ & Saúde e Sociedade & 2013 \\
\hline 5 & Cediel $\mathrm{N}$ et al. & $\begin{array}{l}\text { Risk perception about zoonoses in immigrant and Italian workers in Nor- } \\
\text { thwestern Italy }\end{array}$ & Rev. de Saúde Pública & 2012 \\
\hline 6 & Waldman TC. & Movimentos migratórios sob a perspectiva do direito à saúde & Rev. de Direito Sanitário & 2011 \\
\hline 7 & $\begin{array}{l}\text { Guerlinguer T, Schmu- } \\
\text { cker R. }\end{array}$ & Transnational migration of health professionals in the European Union & $\begin{array}{l}\text { Cadernos de Saúde Pú- } \\
\text { blica }\end{array}$ & 2007 \\
\hline 8 & $\begin{array}{l}\text { Varella TC, Pierantoni } \\
\text { CR. }\end{array}$ & A migração de enfermeiros: um problema de saúde pública & $\begin{array}{l}\text { Rev. Bras. de Saúde Ma- } \\
\text { terno-Infantil }\end{array}$ & 2007 \\
\hline 9 & $\begin{array}{l}\text { López JRG, Gázquez } \\
\text { MAR, Campos MML. }\end{array}$ & $\begin{array}{l}\text { Use of health services by adult Latin American immigrants residing in } \\
\text { Seville }\end{array}$ & $\begin{array}{l}\text { Investigación y Educación } \\
\text { en Enfermería }\end{array}$ & 2014 \\
\hline 10 & Cabieses B et al. & $\begin{array}{l}\text { Changing patterns of migration in Latin America: how can research deve- } \\
\text { lop intelligence for public health? }\end{array}$ & $\begin{array}{l}\text { Rev. Panam. de Salud } \\
\text { Publica }\end{array}$ & 2013 \\
\hline 11 & Goldberg A, Silveira C. & $\begin{array}{l}\text { Desigualdad social, condiciones de acesso a la salud pública y procesos de } \\
\text { atención en inmigrantes bolivianos de Buenos Aires y São Paulo }\end{array}$ & Saúde e Sociedade & 2013 \\
\hline 12 & Cabieses B, Tunstall H. & Immigrant health workers in Chile: is there a Latin American "brain drain"? & $\begin{array}{l}\text { Rev. Panam. de Salud } \\
\text { Publica }\end{array}$ & 2012 \\
\hline 13 & Bustamante AV et al. & $\begin{array}{l}\text { United States-Mexico cross-border health insurance initiatives: Salud } \\
\text { Migrante and Medicare in Mexico }\end{array}$ & $\begin{array}{l}\text { Rev. Panam. de Salud } \\
\text { Publica }\end{array}$ & 2012 \\
\hline 14 & $\begin{array}{l}\text { Coutinho MPL, Oliveira } \\
\text { MX. }\end{array}$ & $\begin{array}{l}\text { Tendências comportamentais frente à saúde de imigrantes brasileiros em } \\
\text { Portugal }\end{array}$ & Psicologia \& Sociedade & 2010 \\
\hline
\end{tabular}




\begin{tabular}{|c|c|c|c|c|}
\hline \multicolumn{5}{|c|}{ Quadro 2. (cont.) } \\
\hline 15 & López JRG et al. & $\begin{array}{l}\text { Conductas de salud em inmigrantes latinoamericanos adultos del Distrito } \\
\text { Macarena de Sevilla (España) }\end{array}$ & $\begin{array}{l}\text { Investigación y Educación } \\
\text { en Enfermería }\end{array}$ & 2010 \\
\hline 16 & $\begin{array}{l}\text { Caballero LV, Solano } \\
\text { VM, Barreto OAA. }\end{array}$ & Globalización y salud en la región San Diego-Tijuana & Gaceta Méd. de México & 2008 \\
\hline 17 & Sotomayor R. & Globalización y la responsabilidad de los países en desarrollo & $\begin{array}{l}\text { Rev. Per. Med. Exp. y Salud } \\
\text { Pública }\end{array}$ & 2007 \\
\hline 18 & Kartzow RV. & $\begin{array}{l}\text { Impacto de las migraciones en Chile. Nuevos retos para el pediatra. Esta- } \\
\text { mos preparados? }\end{array}$ & Rev. Chilena de Pediatria & 2009 \\
\hline 19 & Moreira MASP et al. & Pensando a saúde na perspectiva dos imigrantes brasileiros em Portugal & $\begin{array}{l}\text { Rev. Gaúcha de Enferma- } \\
\text { gem }\end{array}$ & 2007 \\
\hline 20 & Alvarado R. & Salud mental en inmigrantes & Rev. Chil. Salud Publica & 2008 \\
\hline 21 & Kang $S$ et al. & The mental health of Korean immigrants in São Paulo, Brasil & $\begin{array}{l}\text { Cadernos de Saúde Pú- } \\
\text { blica }\end{array}$ & 2009 \\
\hline 22 & Livingston IL et al. & $\begin{array}{l}\text { Gender, acculturative stress and caribbean immigrants' health in the Uni- } \\
\text { ted States of America. }\end{array}$ & $\begin{array}{l}\text { West Indian Medical } \\
\text { Journal }\end{array}$ & 2007 \\
\hline 23 & Silva Al, Dawson MT. & $\begin{array}{l}\text { The impact of international migration on health of brazilian women living } \\
\text { in Australia }\end{array}$ & $\begin{array}{l}\text { Texto \& Contexto Enfer- } \\
\text { magem }\end{array}$ & 2004 \\
\hline 24 & Patarra NL. & Migrações internacionais de e para o Brasil contemporâneo & São Paulo em Perspectiva & 2005 \\
\hline
\end{tabular}

Fonte: Elaboração própria a partir da Lilacs, 2015.

A maior parte dos estudos utilizou uma abordagem quantitativa (9) dos dados. Também foi importante o número de ensaios teóricos (8) entre as publicações selecionadas. Além destes, quatro deles utilizaram um desenho metodológico misto, isto é, tanto quantitativo como qualitativo, e apenas três utilizaram enfoque puramente qualitativo. Nesse contexto, faz-se urgente o desenvolvimento de estudos qualitativos a respeito das condições de vida, trabalho e saúde das várias populações migrantes, uma vez que essa abordagem metodológica é capaz de incorporar com profundidade as questões do 'significado' e da 'intencionalidade' (MINAYO, 2008, P. 22) ao conhecimento científico.

Quatro categorias emergiram da análise dos textos: (1) fluxos migratórios: aspectos teóricos, direções e características; (2) condições de vida e trabalho dos imigrantes; (3) processo saúde-doença; e (4) ações do Estado capitalista e do setor saúde.

\section{Fluxos migratórios: aspectos teóri- cos, direções e características}

Inicialmente, é importante notar que alguns autores oferecem um conjunto de definições e teorias explicativas buscando compreender a migração no mundo atual. Por exemplo, Moreira et al. (2007, P. 528) apresentam o seguinte conceito:

Imigrar, no sentido da palavra propriamente dita, significa entrar em um país que não é o seu de origem para ali viver ou passar um período de sua vida.

De acordo com Coutinho e Oliveira (2010, p. 548), "O termo migração deriva do latim migrare, ou seja, passar de um local para outro".

Kartzow (2009, P. 162), por sua vez, afirma que "o fenômeno migratório é tão antigo quanto a história do mundo". Desde o surgimento do ser humano, ele tem constantemente se deslocado de um lugar a outro no globo, em busca de melhores condições. Mesmo no Brasil, a imigração não é um fato recente: o País é alvo de imigrações internacionais desde a sua invasão pelos portugueses, em 1500. Em finais do século XIX e inícios do século XX, por exemplo, europeus de diversas nacionalidades tiveram como destino este país.

Por outro lado, apesar da característica 
de ser praticamente 'natural' ao ser humano, diversos autores apontam uma mudança recente no volume e nos padrões migratórios em todo o mundo. Isto é, eles estão bastante relacionados com questões econômicas, sociais, políticas e históricas. Os processos globais de fundo que auxiliam na compreensão desses fenômenos dizem respeito às crises recentes do capitalismo, à globalização e reestruturação da economia, à divisão internacional do trabalho e internacionalização dos mercados (PATARRA, 2005; LIVINGSTON ET AL., 2007; SOTOMAYOR, 2007; VARELLA; PIERANTONI, 2007; COUTINHO; OLIVEIRA, 2010; CABIESES ET AL., 2013).

Os autores têm utilizado a ideia de fatores de expulsão (push factors) e de atração (pull factors) para explicar os fluxos migratórios. Fatores de expulsão seriam as altas taxas de violência, baixos salários, alto custo de vida, desemprego, terrorismo, guerras e violação de direitos humanos, entre outros. Em contrapartida, fatores de atração diriam respeito a altos salários, melhores condições de vida e trabalho e acesso a bens e serviços (SOTOMAYOR, 2007; ALVARADO, 2008; KARTZOW, 2009).

Na América Latina, historicamente, três padrões migratórios se destacam: (1) transoceânico, entre meados do século XIX e $\mathrm{XX}$, com um forte componente europeu; (2) intrarregional, principalmente entre os anos 1970 e 1990, relacionado com as desigualdades entre os países da região; e (3) migração Sul-Norte, nas últimas décadas, resultante da perda de trabalhadores qualificados do continente para os países centrais. Contudo, a migração intrarregional (Sul-Sul) tem voltado a crescer mais recentemente, devido ao acirramento na desigualdade entre os países. Esse fenômeno possui um importante contingente feminino (ALVARADO, 2008; KARTZOW, 2009; CABIESES ET AL., 2013). O Chile, por exemplo, tem atraído um número crescente de imigrantes. Em 2006, mais de 70\% deles vieram de outros países da América Latina, principalmente Argentina, Bolívia, Equador e Peru (CABIESES; TUNSTALL, 2012).

Uma região de grande circulação de imigrantes destacada pelos estudos é a fronteira entre México e EUA. Essa região reflete o contraste real entre os países desenvolvidos e em desenvolvimento (CABALLERO; SOLANO; BARRETO, 2008). Segundo Bustamante et al. (2012, P. 74), aproximadamente 30 milhões de "Mexican-Americans" vivem nos EUA, dos quais 12 milhões nasceram fora do país. Imigrantes mexicanos correspondem à maior parte $(57 \%)$ dos imigrantes não documentados nos EUA. Além disso, cerca de 50 milhões de pessoas cruzam a fronteira entre San Diego (EUA) e Tijuana (México) por ano. A travessia pelas áreas desérticas do México e dos EUA, na tentativa da imigração para este último, representa um alto risco de morte (CABALLERO; SOLANO; BARRETO, 2008).

No Brasil, país com 1,5 milhão de imigrações recentes (MARTES; FALEIROS, 2013), destacam-se os estudos referentes aos bolivianos que vivem na cidade de São Paulo. Essa população começou a chegar à cidade na década de 1950, com uma intensificação a partir de 1980. Mais recentemente, as estimativas chegaram a apontar a existência de cerca de 200 mil bolivianos no local (AGUIAR; MOTA, 2014). Eles têm se concentrado no bairro do Bom Retiro, morando e trabalhando em ateliês de costura e confecção, em situação informal e bastante precária (WALDMAN, 2011; GOLDBERG; SILVEIRA, 2013; AGUIAR; MOTA, 2014). Além dos bolivianos, esse bairro foi marcado, desde sua origem, pela presença de diversas etnias. Uma delas diz respeito aos coreanos, que começaram a chegar ao Brasil em 1963. Em 2009, eles chegavam a 50 mil indivíduos (KANG ET AL., 2009).

Além da entrada de imigrantes, o Brasil também é responsável por um considerável fluxo de indivíduos para outros países, sobretudo aqueles ditos 'centrais', como EUA, Itália, Portugal, Espanha e Japão (PATARRA, 2005). Em Portugal, por exemplo, Moreira et al. (2007) estimavam uma população de mais de 100 mil brasileiros. Na Austrália, país tradicionalmente receptor, a presença deles começou a ser notada na segunda metade da década de 1980 (SILVA; DAWSON, 2004). Além desses países, o Paraguai também tem recebido diversos 
brasileiros. Por fim, Patarra (2005, P. 25) conclui que "Embora de diminuta expressão numérica, a entrada e saída de pessoas do território nacional nunca cessou".

\section{Condições de vida e trabalho dos imigrantes}

Para Coutinho e Oliveira (2010), a migração não implica apenas o deslocamento espacial, pois constitui uma experiência de perda, ruptura e mudança. Ela pode ser vivenciada de forma traumática ou harmoniosa, positiva ou negativa, dependendo dos recursos possuídos pelo indivíduo e das características da sociedade receptora. Nesse contexto, a questão da língua é crucial, porque pode ser o estopim de conflitos entre imigrantes e nativos. Muitos nativos podem ver o imigrante com desconfiança, principalmente quando existe a percepção de que ele poderá competir pelos bens, serviços públicos e postos de trabalho do local, o que pode alavancar o preconceito e a discriminação (WALDMAN, 2010).

Alguns pesquisadores têm se debruçado, na última década, sobre a experiência de latino-americanos em países da Europa, EUA e Austrália. Destaca-se a presença massiva de mulheres nessas populações (SILVA; DAWSON, 2004; LIVINGSTON ET AL., 2007; LÓPEZ; GÁZQUEZ; CAMPOS, 2014). É apontada, também, a desigualdade entre os gêneros: entre os caribenhos na região de Maryland, nos EUA, os homens recebiam em média melhores salários do que as mulheres, e estavam em melhores condições de saúde mental e física (LIVINGSTON ET AL., 2007). Essas populações sofrem com o desemprego, a falta de apoio social e a ilegalidade (LÓPEZ; GÁZQUeZ; CAMPOS, 2014). Em Portugal, os brasileiros com menor tempo de permanência e mais jovens eram os que mais se encontravam em situação ilegal (COUTINHO; OLIVEIRA, 2010).

Entre os bolivianos em São Paulo e Buenos Aires, a maior parte também é composta por mulheres. Essa população trabalha majoritariamente no setor têxtil, em ateliês de costura e confecção, morando nesses mesmos locais, principalmente nos bairros mais pobres, insalubres e precários. Eles estão em situação de trabalho desumana e com vínculos informais, em condições similares à escravidão. Além disso, sofrem com barreiras na língua e discriminação (GOLDBERG; SILVEIRA, 2013; MARTES; FALEIROS, 2013).

Os ateliês de costura e confecção "são utilizados pelos empresários locais para evitar encargos, diminuir custos e maximizar os lucros, externalizando a produção" (GOLDBERG; SILVEIRA, 2013, P. 285, TRADUÇÃO NOSSA). Goldberg e Silveira (2013, P. 288, TRADUÇÃO NOSSA) descrevem sucintamente as péssimas condições de trabalho a que estão submetidos os bolivianos na indústria têxtil de Buenos Aires. Essa situação vai

[...] desde a angústia sofrida pela violência e maus tratos, passando pela escassa circulação do ar, o isolamento e a falta de luz solar, a acumulação de pó e umidade nas paredes, solo e teto; até o fato de que o trabalho se realiza em condições de aglomeração, em habitações sem ventilação infestadas de retaIhos de tecidos, fios, poeira e penugens que as máquinas produzem [...]; que a quantidade de horas diárias trabalhadas seja entre $14 \mathrm{e}$ 18, com ritmos intensos e ininterruptos; que a alimentação seja escassa e deficiente, etc. Todos estes elementos, em conjunto, podem gerar uma baixa no sistema imunológico destas pessoas, tornando-as mais vulneráveis à infecção, contágio e desenvolvimento de tuberculose.

Condições de vida e trabalho extremamente precárias também são enfrentadas pelos guatemaltecos que laboram nos cafezais de Chiapas, no sul do México. Esse fluxo migratório é sazonal e familiar, incorporando grandes contingentes de crianças e adolescentes. O trabalho que as famílias desenvolvem se concentra no corte, limpeza e transporte de café (AYALA-CARRILLO ET AL., 2013).

A população infantil, além de auxiliar na 
colheita nas fazendas - nas quais chega a permanecer até 12 horas por dia -, também é responsável pelo trabalho doméstico. Tratase de um trabalho "invisível e pouco valoriZado" (AYALA-CARRILLO ET AL., 2013, P. 661, TRADUĈ̣̃O NOSSA). À criança, paga-se menos, pois seu ofício é considerado 'ajuda', e não trabalho. O abuso, a flexibilidade da força de trabalho imigrante e a violação dos direitos humanos tornam esse setor bastante competitivo internacionalmente. As 'gallera' (AYALA-CARRILLO ET AL., 2013), onde vivem esses indivíduos, são espaços insalubres, sem janelas ou ventilação e com pouca luz. As pessoas dormem em tábuas ou até no próprio chão. Esses estabelecimentos oferecem aos fazendeiros e empresários uma forma de controle da vida dos imigrantes devido às condições de isolamento.

\section{Processo saúde-doença}

Por serem grupos minoritários, Coutinho e Oliveira (2010) afirmam que os imigrantes possuem maior propensão a fatores estressantes do cotidiano. Isso também decorre devido à precariedade das suas condições de vida e trabalho, à discriminação e ao isolamento social. Tendem a reunir, assim, um número mais grave de patologias. Alvarado (2008) salienta que há mais de sete décadas se reconhece o processo migratório como um fator de risco para a saúde mental. Nesse contexto, deve ser considerada a especificidade de cada caso: país de origem e de destino, cultura, contexto social e familiar, apoio social etc.

As crianças e adolescentes guatemaltecos trabalhadores dos cafezais de Chiapas, no México, sofrem com desnutrição, analfabetismo, acidentes de trabalho, infecções respiratórias agudas e gastrointestinais. Os acidentes durante os cortes de 'machete' e quedas foram os mais reportados (AYALACARRILLO ET AL., 2013).

Em Buenos Aires, os bolivianos enfrentam um sério problema com os casos de tuberculose, que vêm crescendo desde 2004. Essa patologia está diretamente relacionada com as condições insalubres de trabalho e moradia a que está exposta essa população. Para Goldberg e Silveira (2013, P. 289, TRADUÇÃO NOSSA), a vulnerabilidade à tuberculose apresentada pelos bolivianos que trabalham e vivem nos ateliês de costura e confecção na cidade

radica, sobretudo, na sua condição de classe subalterna e quase escrava na sociedade argentina, e não em uma suposta predisposição genética, origem geográfica ou identidade étnica.

Na cidade de São Paulo, enquanto os casos de tuberculose diminuíram $45 \%$ na população nativa nos últimos anos, entre os bolivianos eles aumentaram cerca de $250 \%$. Os problemas de saúde de que padecem esses indivíduos, além da tuberculose, incluem: alergias, problemas posturais e de articulação, alcoolismo, violência doméstica, atraso no desenvolvimento psicofísico de crianças, problemas psicológicos e alimentação inadequada. Esses problemas de saúde estão intimamente relacionados com as condições de vida e trabalho dos bolivianos (GOLDBERG; SILVEIRA, 2013).

Pesquisas sobre a saúde dos imigrantes latino-americanos na Espanha e Portugal evidenciaram que se trata de uma população jovem e saudável com perfil epidemiológico parecido com os nativos (MOREIRA ET AL., 2007; HERNANDO ET AL., 2013; LÓPEZ; GÁZQUEZ; CAMPOS, 2014). Contudo, López et al. (2010) destacam a presença de sobrepeso e obesidade nessa população. As brasileiras residentes na Austrália, estudadas por Silva e Dawson (2004), reportaram bom estado de saúde no período da imigração. Durante a pesquisa, câncer (5), febre do feno (5), hipertensão (5), asma (4), artrite (3) e ataque de pânico (2) foram as patologias mais frequentemente mencionadas.

Em pesquisa realizada no setor agroindustrial e pecuário no norte da Itália, constatou-se que a população imigrante proveniente principalmente da Romênia, 
Marrocos, Albânia e Índia - apresentava desvantagens no enfrentamento de diversos problemas de saúde, devido a questões culturais, linguísticas, familiares, sociais e do sistema de saúde. Nesse cenário, os trabalhadores imigrantes perceberam que não havia risco de zoonoses nas atividades de trabalho que desenvolviam em uma frequência maior que os nativos. Isto é, a percepção do risco no trabalho estava comprometida entre os imigrantes (CEDIEL ET AL., 2012).

A partir da análise crítica dos estudos incluídos na revisão, é possível afirmar que poucos deles incorporaram a categoria trabalho como um componente central da saúde dos imigrantes. Apenas quatro pesquisas articularam de forma decidida as dimensões da saúde, do trabalho e da imigração: Varella e Pierantoni (2007), Ayalla-Carrillo et al. (2013), Goldberg e Silveira (2013) e Aguiar e Mota (2014). Os demais ou nem mencionam a categoria trabalho, ou apenas a utilizam como mais um dos múltiplos 'fatores' que interferem na vida e na saúde do imigrante. Ou seja, os estudos pouco avançam na noção de 'determinação social da saúde' - principalmente no seu componente relacionado ao trabalho - e, na sua maioria, permanecem presos à perspectiva de 'determinantes': uma série de fatores sociais apresentados de forma desconexa, com suas relações dialéticas de determinação ocultas em uma roupagem que privilegia comportamentos individuais (ALBUQUeRQUE; SILVA, 2014). Assim, a imigração seria um dentre os diversos fatores que influenciam a saúde individual e coletiva. Desconsidera-se que o próprio processo migratório é determinado socialmente.

Ao considerar a premissa da centralidade do trabalho nas sociedades humanas, desde os seus primórdios até os dias atuais (ANTUNES, 1995), torna-se impossível, ao desprezá-la, compreender o fenômeno migratório em sua totalidade. $\mathrm{O}$ conceito de mobilidade do trabalho, proposto por Gaudemar (1977), possui um importante potencial de agregar elementos na explicação desse processo. Ele trata das formas como o capital produz, explora, faz circular e controla, tanto pelo lado da oferta como pela demanda, a força de trabalho como mercadoria essencial ao processo de acumulação capitalista. (GOMES, 2009, P. 33).

Uma dessas formas se dá por meio dos fluxos migratórios. Nesse sentido, a mobilidade do trabalho deriva do fato de que, no capitalismo, o trabalhador é livre para vender onde queiram comprar a única mercadoria de que dispõe, a sua força de trabalho. As migrações são, assim, produtos dos desígnios da acumulação capitalista e devem atender inteiramente a eles (PERPETUA, 2013).

É claro que existem decisões individuais e fatores de atração e expulsão que estão imbricados nesses fluxos. Contudo, esses elementos permanecem desconexos e insuficientes se for considerada a complexidade do capitalismo mundial, no qual a força de trabalho tem pouca liberdade para escolher o seu destino, seja individual ou coletivamente. Como afirma Basso (2013, P. 36), "as migrações internacionais não são uma somatória banal de histórias individuais".

\section{Ações do Estado capitalista e do se- tor saúde}

Os Estados nacionais, em geral, buscam controlar os fluxos migratórios, levando em conta as necessidades da acumulação capitalista nacional. Na fronteira entre México e EUA, o controle das migrações é bastante rígido, sobretudo quando elas provêm do país 'menos desenvolvido'. O Programa Salud Migrante está sendo desenvolvido pelo Estado mexicano com o objetivo de assegurar o acesso aos serviços de saúde pelos 'Mexican-Americans'. Por outro lado, a iniciativa do Medicare in Mexico, pelo governo estadunidense, visa cobrir a atenção à saúde de uma crescente população do país, principalmente aposentados, que atravessa a fronteira em busca de menor custo de vida, mas não encontra um sistema de saúde eficiente (BUSTAMANTE ET AL., 2012). 
O chamado brain drain, ou 'fuga de cérebros', é outro problema enfrentado pelos países periféricos. Ele ocorre quando profissionais qualificados migram de um país periférico a outro, central. Esse fenômeno é frequente entre profissionais de saúde, que são atraídos por melhores condições de vida, trabalho e progressão na carreira. A União Europeia (EU), por exemplo, tem se preocupado com essa questão, uma vez que a integração transnacional suporia o livre movimento de bens, serviços, capitais e força de trabalho (GERLINGUER; SCHMUCKER, 2007).

No Brasil, o controle da entrada de estrangeiros é realizado pelos Ministérios da Justiça, das Relações Exteriores e do Trabalho e Emprego; respeita-se a Lei ${ }^{\circ}$ 6.815 de 1980 (BRASIL, 1980). Por seu histórico de país receptor de correntes migratórias, o País não parece apresentar restrições à chegada de estrangeiros. No entanto, segundo Waldman (2011, P. 92), isso dissimula a realidade: o viés adotado pela política migratória brasileira é seletivo e restritivo à entrada dos considerados “indesejáveis". Para Villen (2014, P. 88), o País vem sendo alvo de uma onda imigratória dupla, de força de trabalho qualificada e não qualificada, diante de fronteiras "altamente seletivas", mas também "estrategicamente porosas". Isto é, aqueles que interessam ao capitalismo nacional - seja por que possuem alta qualificação ou, pelo contrário, por possuírem baixo valor de sua força de trabalho - têm sua entrada estrategicamente facilitada. Isso ocorre por que a imigração - quando controlada, seletiva e restritiva - é funcional a acumulação capitalista (BASSO, 2013).

Algumas ações do setor saúde parecem se opor ao caráter geral das atuações do Estado no campo das imigrações. Em São Paulo, por exemplo, alguns serviços de atenção básica têm incluído bolivianos como Agentes Comunitários de Saúde (ACS), para facilitar a mediação com a população de imigrantes. No entanto, esse avanço ainda não é capaz de responder totalmente aos problemas enfrentados e às demandas desse grupo (GOLDBERG; SILVEIRA,
2013; MARTES; FALEIROS, 2013). Isso decorre, em parte, da essência contraditória das políticas sociais, que são, ao mesmo tempo, respostas às exigências do capital e às lutas e conquistas da classe trabalhadora (FALEIROS, 2006).

\section{Considerações finais}

De modo geral, os estudos apontaram a precariedade das condições de vida, trabalho e saúde das populações imigrantes. Nesse contexto, o Estado se coloca em uma posição de defesa da acumulação do capital, mesmo que isso signifique a pauperização dessas populações. As iniciativas em sentido contrário ainda são bastante limitadas.

Em relação à tríade saúde-trabalho-imigração, são poucos os estudos que envolvem essas três dimensões de forma simultânea. Desta forma, entre as pesquisas relacionadas neste artigo, a imigração é tratada sob a ótica da saúde, deixando-se o trabalho em segundo plano; poucos estudos agregam esses dois conceitos, que são fundamentais para a compreensão da saúde no escopo da sua determinação social.

Além disso, grande parte dos textos utiliza a ideia de push e pull factors no trato da imigração. Não devem ser desconsideradas as contribuições dessa teoria, porém, é importante avançar nessa discussão, buscando superar seus limites e contradições. Nesse sentido, a teoria da mobilidade do trabalho é uma alternativa, por incorporar a ideia da centralidade do trabalho nas sociedades e por prosperar na concepção de determinação social da imigração.

Portanto, a realização de pesquisas que abordem o fenômeno migratório na perspectiva do trabalho e da saúde ou, mais precisamente, na perspectiva da saúde do trabalhador, ainda permanece um desafio e uma lacuna a ser preenchida por pesquisadores do campo.

Apesar de a pesquisa bibliográfica ter incorporado apenas a base de dados da 
Lilacs, foi possível vislumbrar, ainda que de modo exploratório, os avanços e limitações dos estudos latino-americanos sobre o problema. Em futuras revisões, sugere-se que outras bases de dados sejam integradas.

Por fim, é preciso considerar que a melhor compreensão da imigração contemporânea pode contribuir para a definição de políticas públicas setoriais e intersetoriais que visem à melhoria nas condições de vida, trabalho e saúde. Ainda, pode contribuir no sentido da criação e fortalecimento de coletivos de imigrantes para a defesa de seus direitos e interesses.

\section{Colaboradores}

Leonardo Dresch Eberhardt foi responsável pela concepção e planejamento da pesquisa, coleta, sistematização e análise dos dados; Ary Carvalho de Miranda realizou a orientação do estudo em todas as suas fases e contribuiu com a redação e revisão crítica do manuscrito.

\section{Referências}

AGUIAR, M. E.; MOTA, A. O Programa Saúde da

Família no bairro do Bom Retiro, SP, Brasil: a comunicação entre bolivianos e trabalhadores de saúde. Interface, Botucatu (SP), v. 18, n. 50, 2014, p. 493-506. Disponível em: <http://www.scielo.br/pdf/icse/ v18n50/1807-5762-icse-1807-576220130040.pdf>. Acesso em: 10 jun. 2016.

\section{ALBUQUERQUE, G. S. C.; SILVA, M. J. S. Sobre a} saúde, os determinantes da saúde e a determinação social da saúde. Saúde em Debate, Rio de Janeiro, v. 38, n. 103, p. 953-965, out./dez. 2014. Disponível em: <http://www.scielo.br/pdf/sdeb/v38n103/0103-1104sdeb-38-103-0953.pdf>. Acesso em: 10 jan. 2016.

ALVARADO, R. Salud mental en inmigrantes. Revista Chiena de Salud Pública, Santiago, v. 12, n. 1, p. 37-41, 2008. Disponível em: <http://repositorio.uchile.cl/ bitstream/handle/2250/129485/Salud-mental-eninmigrantes.pdf? sequence=1>. Acesso em: 10 jun. 2016 .

ALVES, G. O novo (e precário) mundo do trabalho. São
Paulo: Boitempo, 2000.

ANTUNES, R. Adeus ao trabalho: ensaio sobre a metamorfose e a centralidade do mundo do trabalho. 3. ed. São Paulo: Cortez, 1995.

ANTUNES, R. Desenhando a nova morfologia do trabalho e suas principais manifestações. In: MERLO, A. R. C.; BOTTEGA, C. G.; PEREZ, K. V. (Org.). Atenção à saúde mental do trabalhador. Porto Alegre: Evangraf, 2014.

AYALA-CARRILLO, M. R. et al. El trabajo infantil guatemalteco en los cafetales del Soconusco: 'insumo' que genera riqueza económica, pero nula valoración social. Revista Latinoamericana de Ciências Sociais, Niñez y Juventud, Manizales, v. 11, n. 2, p. 659-673, 2013. Disponível em: <http://biblioteca.clacso.edu.ar/ Colombia/alianza-cinde-umz/20140715015411/art. MariaDelRosarioAyala.pdf >. Acesso em: 10 jun. 2016.

BASSO, P. Imigração na Europa. In: ANTUNES, R. 
(Org.). Riqueza e miséria do trabalho no Brasil II. São Paulo: Boitempo, 2013. p. 29-41.

BRASIL. Lei n. 6.815, de 19 de agosto de 1980. Define a situação jurídica do estrangeiro no Brasil, cria o Conselho Nacional de Imigração, e dá outras providências. Diário Oficial [da] União, Brasília, DF, 21 ago. 1980. Disponível em: <https://www.planalto.gov.br/ ccivil_03/leis/16815.htm>. Acesso em: 15 ago. 2016.

BUSTAMANTE, A. V et al. United States-Mexico cross-border health insurance initiatives: Salud Migrante and Medicare in Mexico. Revista Panamericana de Salud Publica, Washington, v. 31, n. 1, p. 74-80, jan. 2012. Disponível em: <https://www.ncbi. nlm.nih.gov/pmc/articles/PMC4018207/>. Acesso em: 15 ago. 2016

\section{CABALLERO, L. V.; SOLANO, V. M.; BARRETO, O.} A. A. Globalización y salud en la región San DiegoTijuana. Gaceta Médca de México, México, v. 144, n. 5, p. 389-394, 2008. Disponível em: <http://www.anmm. org.mx/GMM/2008/n5/21_vol_144_n5.pdf >. Acesso em: 15 ago. 2016.

CABIESES, B.; TUNSTALL, H. Immigrant health workers in Chile: is there a Latin American brain drain. Revista Panamericana de Salud Publica, Washington, v. 32, n. 2, p. 161-167, 2012. Disponível em: <http://www. scielosp.org/pdf/rpsp/v32n2/v32n2a12.pdf >. Acesso em: 16 ago. 2016.

CABIESES, B. et al. Changing patterns of migration in Latin America: how can research develop intelligence for public health. Revista Panamericana de Salud Publica, Washington, v. 34, n. 1, p. 68-74, 2013. Disponível em: <http://www. scielosp.org/scielo.php?script=sci_arttext\&pid $=$ S1020-49892013000700010>. Acesso em: 16 ago. 2016

CEDIEL, N. et al. Risk perception about zoonoses in immigrant and Italian workers in Northwestern Italy. Revista de Saúde Pública, São Paulo, v. 46, n. 5, p. 850857, 2012. Disponível em: <http://www.scielo.br/pdf/ rsp/v46n5/12.pdf>. Acesso em: 16 ago. 2016.

COUTINHO, M. P. L.; OLIVEIRA, M. X. Tendências comportamentais frente à saúde de imigrantes brasileiros em Portugal. Psicologia \&t Sociedade, Belo Horizonte, v. 22, n. 3, 2010, p. 548-557. Disponível em: <http://www.scielo.br/pdf/psoc/v22n3/v22n3al5.pdf > . Acesso em: 16 ago. 2016.

FALEIROS, V. P. O que é politica social. São Paulo: Brasiliense, 2006.

FLEURY-TEIXEIRA, P. Uma introdução conceitual à determinação social da saúde. Saúde em Debate, Rio de Janeiro, v. 33, n. 83, p. 380-387, set./ dez. 2009. Disponível em: <http://www.redalyc.org/ pdf/4063/406345800005.pdf >. Acesso em: 16 ago. 2016.

GAUDEMAR, J. P. O conceito marxista de mobilidade do trabalho. In Mobilidade do trabalho e acumulação do capital. Lisboa: Estampa, 1977. p. 185-211.

GERLINGUER, T.; SCHMUCKER, R. Transnational migration of health professionals in the European Union. Cadernos de Saúde Pública, Rio de Janeiro, v. 23, sup. 2, p. 184-192, 2007. Disponível em: <http://www. scielo.br/scielo.php?script=sci_arttext\&pid=S0102-311X2007001400008>. Acesso em: 16 ago. 2016.

GIL, A. C. Como elaborar projetos de pesquisa. 4. ed. São Paulo: Atlas, 2002.

GOLDBERG, A.; SILVEIRA, C. Desigualdad social, condiciones de acesso a la salud pública y procesos de atención en inmigrantes bolivianos de Buenos Aires y São Paulo: una indagación comparativa. Saúde e Sociedade, São Paulo, v. 22, n. 2, p. 283-297, 2013. Disponível em: <http://www.scielo.br/pdf/sausoc/ v22n2/v22n2a03.pdf $>$. Acesso em: 16 ago. 2016.

GOMES, F. G. Mobilidade do trabalho e controle social: trabalho e organizações na era neoliberal. Revista Sociologia e Política, Curitiba, v. 17, n. 32, p. 33-49, fev. 2009. Disponível em: <http://www.scielo.br/scielo. php?pid=S0104-44782009000100003\&script=sci_ abstract\&tlng=es>. Acesso em: 16 ago. 2016.

HERNANDO, A. et al. A comparative study on the health and well-being of adolescent immigrants in Spain 
and Portugal. Saúde e Sociedade, São Paulo, v. 22, n. 2, p. 342-350, 2013. Disponível em: <http://www.uhu.es/angel.hernando/documentos/2013_Saude_e_Sociedade. pdf $>$. Acesso em: 16 ago. 2016.

KANG, S. et al. The mental health of Korean immigrants in São Paulo, Brasil. Cadernos de Saúde Pública, Rio de Janeiro, v. 25, n. 4, p. 819-826, abr. 2009. Disponível em: <http://www.scielo. $\mathrm{br} /$ scielo.php?script=sci_arttext\&pid=S0102-311X2009000400013>. Acesso em: 16 ago. 2016.

KARTZOW, R. V. Impacto de las migraciones en Chile. Nuevos retos para el pediatra. Estamos preparados? Revista Chilena de Pediatria, Santiago, v. 80, n. 2, p. 161167, 2009. Disponível em: <http://www.scielo.cl/scielo. php?pid=S0370-41062009000200009\&script=sci_arttext>. Acesso em: 16 ago. 2016.

LIVINGSTON, I. L. et al. Gender, acculturative stress and caribbean immigrants' health in the United States of America. An exploratory study. West Indian Medical Journal, Kingston, v. 56, n. 3, p. 213-222, 2007.

LÓPEZ, J. R. G.; GÁZQUEZ, M. A. R.; CAMPOS, M. M. L. Use of health services by adult Latin American immigrants residing in Seville. Investigación Educación Enfermagem, Medellín, v. 32, n. 2, p. 347-355, 2014.

LÓPEZ, J. R. G. et al. Conductas de salud en inmigrantes latinoamericanos adultos del Distrito Macarena de Sevilla (España). Investigación Educación Enfermagem, Medellín, v. 28, n. 3, p. 385-395, 2010.

MARTES, A. C. B.; FALEIROS, S. M. Acesso dos imigrantes bolivianos aos serviços públicos de saúde na cidade de São Paulo. Saúde e Sociedade, São Paulo, v. 22, n. 2, p. 351-364, 2013. Disponível em: <http://www. scielo.br/pdf/sausoc/v22n2/v22n2a08.pdf > . Acesso em: 16 ago. 2016.

MINAYO, M. C. S. O desafio do conhecimento. 11. ed. São Paulo: Hucitec, 2008.

MINAYO, M. C. S. Análise qualitativa: teoria, passos e fidedignidade. Ciência \&t Saúde Coletiva, Rio de Janeiro, v. 17, n. 3, p. 621-626, 2012. Disponível em: <http://www.scielo.br/scielo.php?pid=S1413$-81232012000300007 \&$ script $=$ sci_abstract\&tlng $=p t>$. Acesso em: 16 ago. 2016.

MINAYO-GOMEZ, C. Campo da saúde do trabalhador: trajetória, configuração e transformações. In: MINAYO-GOMEZ, C.; MACHADO, J. M. H.; PENA, P. G. L. (Org.). Saúde do trabalhador na sociedade brasileira contemporânea. Rio de Janeiro: Fiocruz, 2011.

MOREIRA, M. A. S. P. et al. Pensando a saúde na perspectiva dos imigrantes brasileiros em Portugal. Revista Gaúcha de Enfermagem, Porto Alegre, v. 28, n. 4, p. 527-533, dez. 2007. Disponível em: <http://seer.ufrgs. br/RevistaGauchadeEnfermagem/article/view/3130>. Acesso em: 16 ago. 2016.

PATARRA, N. L. Migrações internacionais de e para o Brasil contemporâneo: volumes, fluxos, significados e políticas. SP em Perspectiva, São Paulo, v. 19, n. 3, p. 2333, jul./set. 2005. Disponível em: <http://www.scielo. br/pdf/spp/v19n3/v19n3a02.pdf>. Acesso em: 16 ago. 2016.

PERPETUA, G. M. Mobilidade espacial do capital e da força de trabalho: elementos para uma teorização geográfica a partir da matriz marxista. Revista Pegada, Presidente Prudente, v. 14, n. 1, p. 58-80, jul. 2013. Disponível em: <http://revista.fct.unesp.br/index.php/ pegada/article/viewFile/2138/2137>. Acesso em: 16 ago. 2016.

SILVA, A. L.; DAWSON, M. T. The impact of international migration on health of brazilian women living in Australia. Texto \& Contexto Enfermagem, Florianópolis, v. 13, n. 3, p. 339-550, jul./set. 2004. Disponível em: $<$ http://www.scielo.br/scielo.php?script=sci_arttext\& pid=S0104-07072004000300002 $>$. Acesso em: 16 ago. 2016.

SOTOMAYOR, R. Globalización y la responsabilidad de los países en desarrollo: el caso de la migración de los profesionales de salud. Revista Peruana de Medicina Experimental y Salud Pública, Lima, v. 24, n. 3, p. 300306, 2007. Disponível em: <http://www.scielo.org.pe/ pdf/rins/v24n3/a16v24n3.pdf >. Acesso em: 16 ago. 2016. 
TAMBELLINI, A. T.; SCHÜTZ, G. E. Contribuição para o debate do CEBES sobre a 'determinação social da saúde': repensando processos sociais, determinações e determinantes da saúde. Saúde em Debate, Rio de Janeiro, v. 33, n. 83, p. 371-379, set./dez. 2009.

UEBEL, R. R. G. Aspectos gerais da dinâmica imigratória no Brasil no Século XXI. In: SEMINÁRIO MIGRAÇÕES INTERNACIONAIS, REFÚGIO E POLÍTICAS, 1., 2006, São Paulo. Anais... São Paulo: MAL/Unicamp, 2016.

UNITED NATIONS. Department of Economical and Social Affairs. International migration report 2015. New York: UN, 2016. Disponível em: < http://www.un.org/ en/development/desa/population/migration/publications/migrationreport/docs/MigrationReport2015_ Highlights.pdf $>$. Acesso em: 16 ago. 2016.

VARELLA, T. C.; PIERANTONI, C. R. A migração de enfermeiros: um problema de saúde pública. Revista Brasileira de Saúde Materno Infantil, Recife, v. 7, n. 2, p.
199-211, abr./jun. 2007. Disponível em: <http://www. scielo.br/pdf/rbsmi/v7n2/11.pdf >. Acesso em: 16 ago. 2016.

VILLEN, P. A nova configuração da imigração no Brasil sob a óptica do trabalho. In: ANTUNES, R. (Org.). Riqueza e miséria do trabalho no Brasil III. São Paulo: Boitempo, 2014.

WALDMAN, T. C. Movimentos migratórios sob a perspectiva do direito à saúde: imigrantes bolivianas em São Paulo. Revista de Direito Sanitário, São Paulo, v. 12, n. 1, p. 90-114, mar./jun. 2011. Disponível em: <http:// www.revistas.usp.br/rdisan/article/view/13239>. Acesso em: 16 ago. 2016.

Recebido para publicação em agosto de 2016

Versão final em dezembro de 2016

Conflito de interesses: inexistente

Suporte financeiro: bolsa (Mestrado em Saúde Pública do autor na Ensp/Fiocruz,) da Fundação Carlos Chagas Filho de Amparo à Pesquisa do Estado do Rio de Janeiro (Faperj) 